\title{
The effects of estrogens on food intake and body weight following ventromedial hypothalamic lesions*
}

\author{
JAMES M. KING and VERNE C. COX \\ University of Texas at Arlington, Arlington, Texas 76010
}

\begin{abstract}
The effects of estrogens on increased food intake and body weight gain induced by ovariectomy were examined in VMHN-lesioned and nonlesioned female rats. Ovariectomy yielded higher food intake and weight gain in VMHN-lesioned rats than that produced by lesions alone. Relatively low dosages of estradiol benzoate were effective in suppressing ovariectomy-induced food intake and weight gain in VMHN-lesioned and nonlesioned animals.
\end{abstract}

The energy balance in the female rat is closely tied to gonadal hormone levels. Cyclic variations in food intake, in the female rat, are governed, in large part, by estrogen levels which vary during the estrus cycle. Food intake is highest during anestrus and lowest during estrus, when serum levels of estrogens are at their lowest and highest levels, respectively (Shaikh, 1971; Tarttelin \& Gorski, 1971). Following ovariectomy, female rats display increased food intake and accelerated body weight gain, which can be reversed by administration of exogenous estrogens (Zucker, 1972). Estrogens are active at many central nervous system sites, including the ventromedial hypothalamic nucleus (VMHN) (Anderson \& Greenwald, 1969; Pfaff, 1968; Stumpf, 1970, 1971). The VMHN has been implicated by many investigators in food-intake suppression, presumably in response to systemic cues such as serum glucose (Mayer \& Thomas, 1967), some correlate of body lipids (Kennedy, 1966), and serum estrogens (Wade \& Zucker, 1970). Wade and Zucker (1970) suggested that the anorexic properties of estrogens were mediated via the VMHN. These investigators reported that estrogens applied to the VMHN were effective in reducing food intake in ovariectomized rats and had no effect on food intake when applied to other sites. In contrast to the hypothesis offered by Wade and Zucker is a published report by Montemurro (1970) and two unpublished reports of estrogenic suppression of food intake in VMHN-lesioned animals (Finger \& Mook, 1971; Reynolds, 1968). Montemurro employed high doses of diethylstilbestrol in male mice, and the other reports involved the administration of estradiol of VMHN-lesioned female rats.

The present study was designed to provide additional information regarding the role of the VMHN in estrogenic suppression of food intake and weight gain. The effects of exogenous and endogenous estrogens on

*This research was supported, in part, by the Organized Research Fund of the University of Texas at Arlington. We wish to acknowledge the invaluable assistance of Ira $\mathrm{H}$. Bernstein, who provided computerized data analyses and statistical advice. Reprint requests should be sent to James M. King or Verne C. Cox. Psychology Department. University of Texas at Arlington. Arlington. Texas 76010 food intake and body weight in VMHN-lesioned female rats was systematically investigated. Estrogen levels were employed that had been previously determined to be the minimal levels required for reinstatement and maintenance of sexual receptivity in ovariectomized rats (Davidson, Smith, Rodgers, \& Block, 1968). Thus, we attempted to approximate the levels of estrogenic activity present during estrus when food intake is at its lowest levels in the female rat.

\section{METHOD}

\section{Subjects}

The Ss were female Holtzman albino rats $(260-270 \mathrm{~g})$. They were housed in individual cages with powdered Purina Lab Chow and water available ad lib. A 12-h light-dark cycle was maintained in the animal quarters.

\section{Procedure}

Preoperative measurements of food intake and body weight were obtained for 10 days. On the day of surgery, all animals were anesthetized with a mixture of chloralhydrate and pentobarbitol and subjected to one of several surgical procedures. Lesioned animals received bilateral lesions of the ventromedial hypothalamic nuclei. With the skull level between bregma and lambda, the tip of the lesion probe was placed $3.0 \mathrm{~mm}$ posterior to bregma, $.5 \mathrm{~mm}$ lateral to the midline, and $.25 \mathrm{~mm}$ above the bottom of the skull. The anodal current used was $2.0 \mathrm{~mA} \mathrm{dc}$ applied for $20 \mathrm{sec}$. All nonlesioned Ss received bilateral skull trephinations. All Ss received bilateral flank incisions, and Ss in six of the eight groups had their ovaries removed. The experiment consisted of four lesioned and four nonlesioned groups, each consisting of eight animals. Two of the lesioned and nonlesioned groups received postoperative daily injections of estradiol benzoate (EB) in oil, and the remaining groups received sesame oil injections of equal volume $(.10 \mathrm{ml})$. Animals in one nonlesioned group and one lesioned group were not ovariectomized. Table 1 lists the eight experimental conditions employed in the study.

Following surgery, food intake and body weight measurements were obtained for 25 days. Beginning with the first postoperative day, all animals received daily injections of either 1.5 or 3.0 micrograms of EB in oil or sesame oil. The dosages of EB employed were the two lowest daily dosages that Davidson et al (1968) found sufficient to reinstate and maintain sexual receptivity in ovariectomized female rats. Daily injections of 1 microgram of EB were reported by Zucker (1972) as minimal dosages sufficient for restoration of normal food intake and weight gain in ovariectomized rats that were somewhat 
Table 1

Lesion and Hormone Conditions

\begin{tabular}{lll}
\hline \multicolumn{1}{c}{ Lesion } & \multicolumn{1}{c}{ Ovaries } & \multicolumn{1}{c}{ Hormone } \\
\hline VMHN Lesion & Ovariectomy & No Hormone \\
VMHN Lesion & Ovariectomy & 1.5 micrograms EB/day \\
VMHN Lesion & Ovariectomy & 3.0 micrograms EB/day \\
VMHN Lesion & Intact & No Hormone \\
Intact & Ovariectomy & No Hormone \\
Intact & Ovariectomy & 1.5 micrograms EB/day \\
Intact & Ovariectomy & 3.0 micrograms EB/day \\
Intact & Intact & No Hormone \\
\hline
\end{tabular}
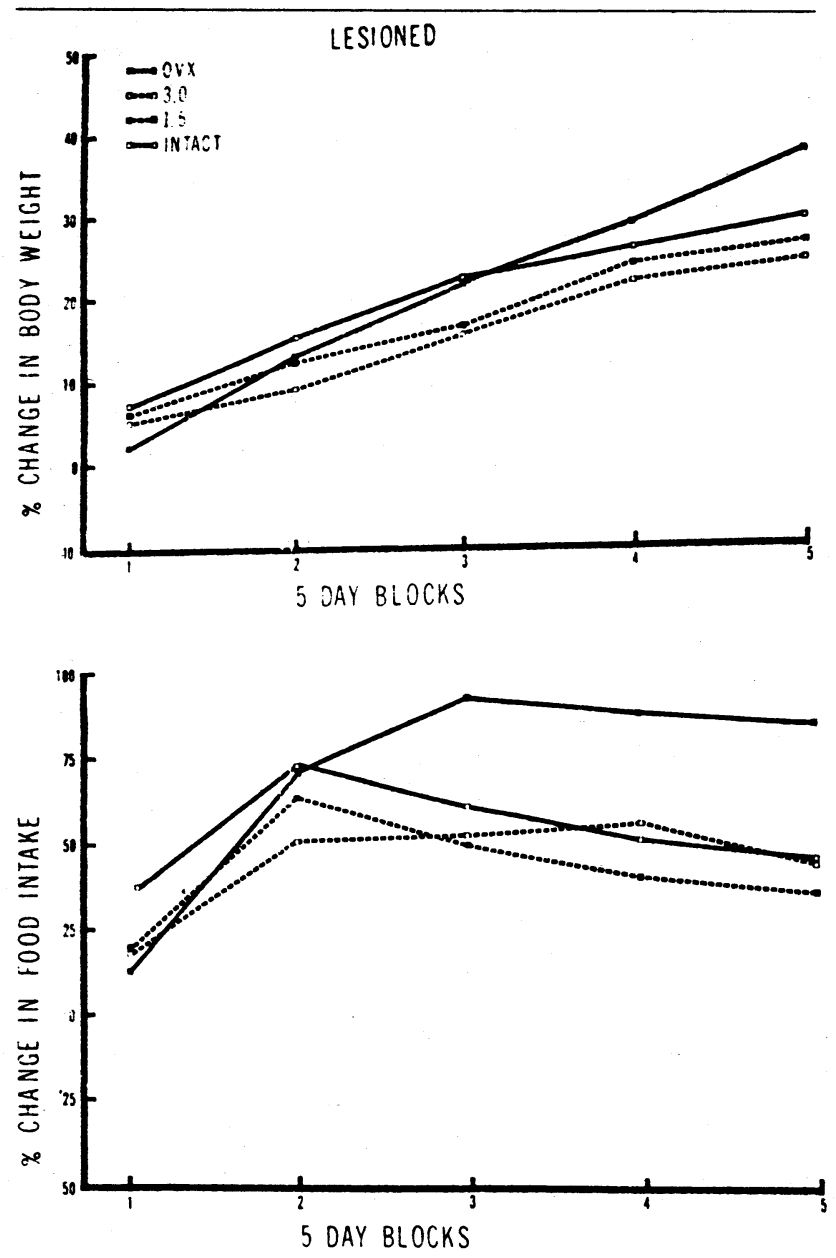

Fig. 1. Percentage change in body weight and food intake in lesioned animals.

lighter than the animals employed in the present study.

At the conclusion of the experiment, Ss were sacrificed with an overdose of anesthetic and perfused intracardially with .9\% saline and $10 \%$ Formalin solutions. Their brains were removed and frozen sections, 60 microns thick, were stained with cresylecht violet and examined microscopically to determine the extent and location of lesions.

\section{Data Analyses}

The data were analyzed using analyses of variance (ANOVA). Repeated measures ANOVAs across 5-day blocks were applied to percentage change scores for body weight and food intake. The percentage change scores employed were relative to the mean of the last five preoperative days for food intake and the last preoperative day for body weight. End-point ANOVAs were used for both percentage change and absolute difference scores for food intake and body weight. Body weight comparisons involved differences between the last preoperative and postoperative day. Food intake comparisons involved the mean of the last 5 pre- and postoperative days.

\section{RESULTS}

\section{Histology}

Each of the four lesion groups consisted of eight animals that met histological criteria for complete bilateral symmetrical destruction of the cross-sectional area of the VMHN at the center of its anterior-posterior extent with minimal damage to adjacent tissue (see Fig. 2; Cox, Kakolewski, \& Valenstein, 1968).

\section{Food Intake}

Figures 1 and 2 present the percentage change values for food intake for the lesioned and nonlesioned groups. Absolute difference scores for food intake are presented in Table 2. A repeated measures ANOVA of percentage
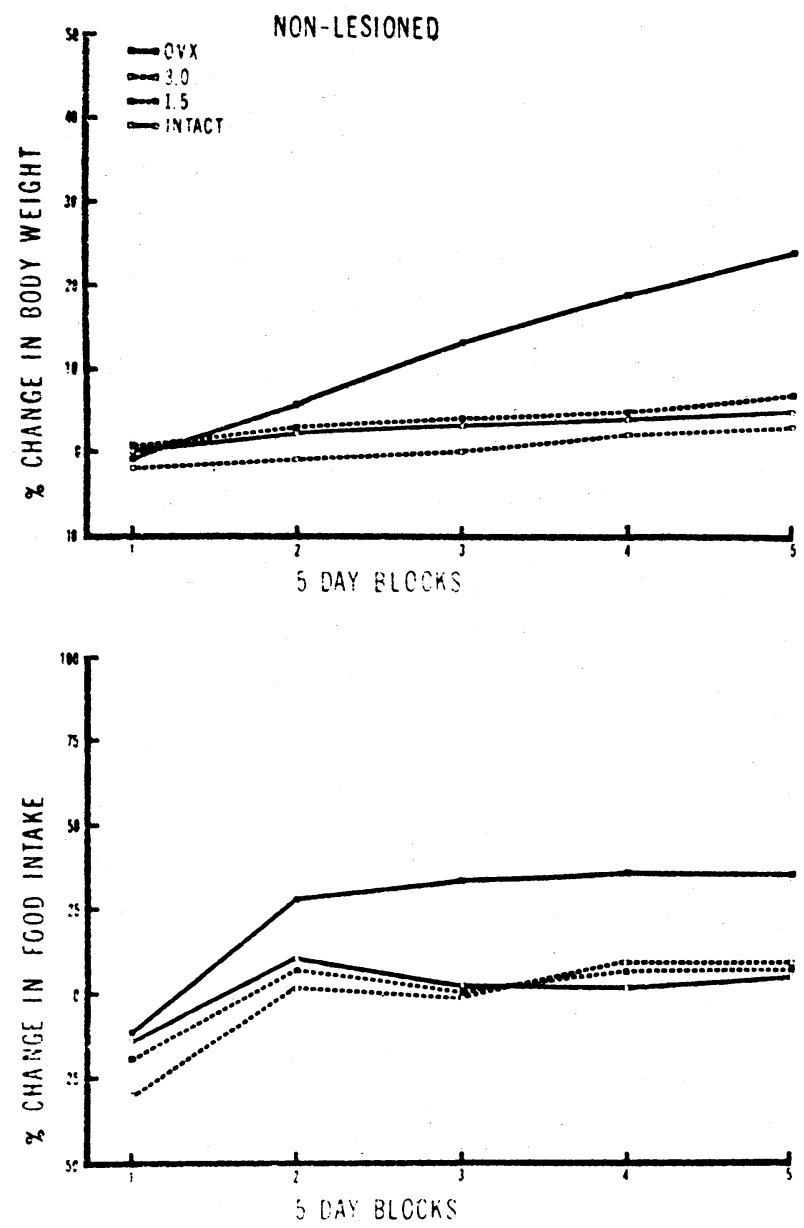

Fig. 2. Percentage change in body weight and food intake in nonlesioned animals. 
Table 2

Mean Changes in Body Weight and Daily Food Intake in Grams

\begin{tabular}{|c|c|c|c|c|c|c|}
\hline Group & $\begin{array}{c}\text { Preoperative } \\
\text { Weight }\end{array}$ & $\begin{array}{c}\text { Postoperative } \\
\text { Weight }\end{array}$ & $\begin{array}{c}\text { Net } \\
\text { Change }\end{array}$ & $\begin{array}{c}\text { Preoperative } \\
\text { Food }\end{array}$ & $\begin{array}{c}\text { Postoperative } \\
\text { Food }\end{array}$ & $\begin{array}{c}\text { Net } \\
\text { Change }\end{array}$ \\
\hline $\begin{array}{l}\text { LES, OVX, NH } \\
\text { LES, OVX, } 1.5 \\
\text { LES, OVX, } 3.0 \\
\text { LES, INT, NH }\end{array}$ & $\begin{array}{l}268 \\
271 \\
266 \\
271\end{array}$ & $\begin{array}{l}362 \\
336 \\
327 \\
346\end{array}$ & $\begin{array}{l}94 \\
65 \\
61 \\
75\end{array}$ & $\begin{array}{l}17.5 \\
10.0 \\
17.2 \\
18.6\end{array}$ & $\begin{array}{l}32.0 \\
26.6 \\
24.5 \\
27.0\end{array}$ & $\begin{array}{r}14.5 \\
6.7 \\
7.3 \\
8.4\end{array}$ \\
\hline $\begin{array}{l}\text { INT, OVX, NH } \\
\text { INT, OVX, } 1.5 \\
\text { INT, OVX, 3.0 } \\
\text { INT, INT, NH }\end{array}$ & $\begin{array}{l}265 \\
270 \\
282 \\
273\end{array}$ & $\begin{array}{l}327 \\
286 \\
284 \\
278\end{array}$ & $\begin{array}{r}62 \\
16 \\
2 \\
5\end{array}$ & $\begin{array}{l}16.8 \\
18.9 \\
19.2 \\
16.3\end{array}$ & $\begin{array}{l}22.7 \\
20.3 \\
20.2 \\
17.6\end{array}$ & $\begin{array}{l}5.9 \\
1.4 \\
1.0 \\
1.3\end{array}$ \\
\hline
\end{tabular}

change scores for food intake yielded a statistically significant hormone main effect, $F(3,56)=5.44$, $\mathrm{p}<.01$, lesion main effect, $\mathrm{F}(1,56)=76.08, \mathrm{p}<.01$, blocks main effect, $F(4,224)=45.48, p<.001$, and Hormone by Blocks interaction, $F(12,224)=4.51$, $\mathrm{p}<.01$. The same statistically significant findings were also obtained with end-point ANOVAs applied to both percentage change and absolute difference scores. In addition, the end-point ANOVA of percentage change scores yielded a significant Hormone by Lesion interaction, $\mathrm{F}(3,56)=4.95, \mathrm{p}<.01$. Orthogonal comparisons of the repeated measures ANOVA for percentage change scores revealed that the comparison, across lesion conditions, of the ovariectomy, no hormone condition vs all other groups was significant, $F(1,56)=15.32, p<.01$, and accounted for $94 \%$ of the hormone sum of squares (Winer, 1971).

\section{Body Weight}

Figures 1 and 2 present the percentage change scores for body weight for the lesioned and nonlesioned groups. Absolute difference scores for body weight are presented in Table 2. A repeated measures ANOVA of percentage change scores for body weight yielded a statistically significant hormone main effect, $F(3,56)=$ $4.42, \mathrm{p}<.01$, lesion main effect, $\mathrm{F}(1,56)=55.59$, $\mathrm{p}<.001$, blocks main effect, $\mathrm{F}(4,224)=146.84$, $\mathrm{p}<.001$, Hormone by Blocks interaction, $\mathrm{F}(12,224)=$ $9.18, \mathrm{p}<.01$, and Lesion by Blocks interaction, $\mathrm{F}(4,224)=220.87, \mathrm{p}<.01$. The same statistically significant relationships were also obtained with end-point ANOVAs applied to both percentage change and absolute difference scores. Orthogonal comparisons of the repeated measures ANOVA for percentage change scores revealed that the comparison, across lesion conditions, of the ovariectomy, no hormone condition vs all other groups was significant, $\mathrm{F}(1,56)=10.57$, $\mathrm{p}<.01$, and accounted for $80 \%$ of the hormone sum of squares.

\section{DISCUSSION}

The hormone effects obtained in the present study were accounted for almost entirely by the differences between the nonhormone conditions vs the hormone conditions in both the lesioned and nonlesioned conditions. The food intake results indicate that female rats with VMHN lesions remain responsive to the anorexic properties of estrogens. The statistically reliable Lesion by Hormone interaction for food intake suggests that VMHN-lesioned animals are actually somewhat more responsive to estrogens than nonlesioned animals. This finding is consistent with a previous report by Montemurro (1971) indicating that VMHN-lesioned mice are supersensitive to the anorexic properties of diethylstilbestrol. The findings of the present study do not provide support for the contention that estrogen-induced food intake suppression is mediated via the VMHN (Wade \& Zucker, 1970). It is likely, however, that estrogen-induced suppression of food intake is due to central nervous system estrogenic action at some site, because intracerebrally applied estradiol benzoate is effective in suppressing food intake when applied in quantities that do not appear to have systemic effects (Wade \& Zucker, 1970). It has been suggested recently (Zucker, 1972) that food intake suppression by estrogens is secondary to estrogenic modulation of a weight regulatory system. To the extent that this hypothesis is correct, it would appear that direct estrogenic modulation of weight gain is not mediated by the VMHN.

The results of the present study also indicate that food intake and body weight changes in VMHN-lesioned female rats are not due, in any substantial way, to ovarian hormone deficiency (Cox, Kakolewski, \& Valenstein, 1969). Removal of the ovaries, in the present study, produced greater hyperphagia in lesioned animals than that induced by VMHN lesions alone. Nor were any differences observed between the lesioned groups that received low dosages of estradiol and the nonovariectomized VMHN-lesioned animals. The alterations in food intake and body weight that result from VMHN lesions and from ovariectomy appear to be independent, and the changes resulting from one of these manipulations can be readily superimposed upon the changes resulting from the other.

\section{REFERENCES}

Anderson. C. H.. \& Greenwald, G. S. Autoradiographic analysis of estradiol in the brain and pituitary of the female rat. Endocrinology. 1969, 85, 1160-1165. 
Cox, V. C., Kakolewski, J. W., \& Valenstein, E. S. The effects of ventromedial hypothalamic damage in hypophysectomized rats. Journal of Comparative \& Physiological Psychology, 1968, 65, 145-148.

Cox, V. C., Kakolewski, J. W., \& Valenstein, E. S. Ventromedial hypothalamic lesions and changes in body weight and food consumption in male and female rats. Journal of Comparative \& Physiological Psychology, 1969, 67, 320-326.

Davidson, J. M., Smith, E. R., Rodgers, C. H., \& Block, G. S. Relative thresholds of behavioral and somatic responses to estrogen. Physiology \& Behavior, 1968, 3, 227-229.

Finger, F. W., \& Mook, D. G. Basic drives. In R. H. Massen and M. R. Rosenweig (Ed.), Annual review of psychology. Palo Alto, Calif: Annual Reviews, 1971. Pp. 1-38.

Kennedy, G. C. Food intake, energy balance and growth. British Medical Bulletin, 1966, 22, 216-220.

Mayer, J., \& Thomas, D. W. Regulation of food intake and obesity. Science, 1967, 156, 328-337.

Montemurro, D. G. Inhibition of hypothalamic obesity in the mouse with diethylstilbestrol. Canadian Journal of Physiology \& Pharmacology, 1971, 49, 554-558.

Pfaff, D. Autoradiographic localization of radioactivity in rat brain after injection of tritiated sex hormones. Science, 1968, $161,1355-1356$.

Reynolds, R. W. Gonadal influences on the hypothalamic regulation of food intake. Third International Conference on the Regulation of Food and Water Intake, Haverford College, Haverford, $\mathrm{Pa} ., 1968$.
Shaikh, A. A. Estrone and estradiol levels in the ovarian venous blood from rats during the estrous cycle and pregnancy. Biology of Reproduction, 1971. 5, 297-307.

Stumpf, W. E. Estrogen-neurons and estrogen-neuron systems in the periventricular brain. American Journal of Anatomy, $1970,129,207-217$.

Stumpf, W. E. Autoradiographic techniques and localization of estrogen, androgen and glucocorticoid in the pituitary and brain. American Zoologist, 1971, 11, 725-739.

Tarttelin, M. F., \& Gorski, R. A. Variations in food and water intake in the normal and acyclic female rat. Physiology \& Behavior. 1971. 7. 847-852.

Wade, G. N., \& Zucker, I. Modulation of food intake and locomotive activity in female rats by diencephalic hormone implants. Journal of Comparative \& Physiological Psychology, $1970,72,328-336$

Winer, B. J. Statistical principles in experimental design. New York: McGraw-Hill, 1971.

Zucker, I. Body weight and age as factors determining estrogen responsiveness in the rat feeding system. Behavioral Biology, $1972,7,527-542$.

(Received for publication May 2, 1973; accepted May 15, 1973.) 